\title{
Three-dimensional reconstruction of the F-actin musculature of Dorvillea kastjani (Dorvilleidae: Polychaeta) by means of phalloidin-labelling and cLSM
}

\author{
ANNA FILIPPOVA ${ }^{1}$, GÜNTER PURSCHKE ${ }^{2}$, ALEXANDER B. TZETLIN $^{1}$ \\ and MONIKA C.M. MÜLLER ${ }^{2}$ \\ ${ }^{1}$ Department of Invertebrate Zoology, Moscow State University, Russia. E-mail: afilippowa@mail.ru \\ ${ }^{2}$ Spezielle Zoologie, Fachbereich Biologie/Chemie, Universität Osnabrück, Germany.
}

\begin{abstract}
SUMMARY: This paper is part of a series investigating the muscular architecture of various "Polychaeta", aiming to ascertain the presence of circular muscles in the body wall, which have recently been thought to be lacking more often than hitherto known. The F-actin muscular subset of Dorvillea kastjani was labelled with phalloidin and the architecture three-dimensionally reconstructed by means of confocal laser scanning microscopy. Three pairs of longitudinal, two transverse and numerous radial muscles ensure shape and flexibility of the prostomium. Mobility of the sub-biramous parapodia and their chaetae is achieved by seven different muscle types. The body wall contains transverse and bracing muscles and in total five longitudinal muscle strands: two dorsolateral, two ventral and one ventromedial. Numerous transverse fibres extend from the dorsal side peripherally and ventrally and become concentrated into six or seven pairs of bundles per segment on the ventral side. They terminate before reaching the midline, leaving a gap of only a few micrometres between them. Within the intersegmental furrows these fibres form complete rings in a supralongitudinal postion. Thus, true circular fibres exist in D. kast-
\end{abstract} jani but are weakly developed.

Keywords: Annelida, body wall, muscle system, evolution.

RESUMEN: RECONSTRUCCIÓN TRIDIMENSIONAL DE LA MUSCULATURA F-ACTINA DE DORVILLEA KASTJANI (DORVILLEIDAE: POLYCHAETA) POR MEDIO DE MARCADO CON PHALLOIDINA Y CLSM. - Este trabajo forma parte de una serie de trabajos que investigan la arquitectura muscular de diferentes especies de Poliquetos con el objetivo de comprobar la presencia de musculatura circular en su cuerpo; recientemente se piensa que dicha musculatura podría estar ausente más a menudo de lo hasta ahora pensado. La musculatura F-actina de Dorvillea kastjani fue marcada con phalloidina y su arquitectura reconstruida tridimensionalmente por medio de microscopia de scanning laser confocal. Tres pares longitudinales, dos tranversales y numerosos músculos radiales aseguran la flexibilidad y la forma del prostómio. La mobilidad de los parápodos sub-biramios y sus quetas se obtiene gracias a siete diferentes tipos de músculos. La cavidad del cuerpo contiene musculos tranversales y diagonales y en total cinco ramas de músculos longitudinales: dos dorsolaterales, dos ventrales y una medioventral. Numerosas fibras transversales se extienden desde la zona dorsal periféricamente y centralmente y se concentran en seis o siete pares de paquetes por segmento en la cara ventral. Estos terminan antes de alcanzar la línea central dejando un vacio de unas micras entre ellos. Entre los surcos entre segmentos, las fibras forman anillos completos en una posición supralongitudinal. Además, verdaderas fibras circulares existen en Dorvillea kastjani pero están débilmente desarrolladas.

Palabras clave: Annelida, pared del cuerpo, sistema muscular, evolución.

\section{INTRODUCTION}

Presence of an outer layer of circular muscle fibres and an inner layer of longitudinal fibres, cor- responding to an oligochaete-like arrangement of the body wall musculature, is generally considered to represent the ground pattern of the muscle system in Annelida (Lanzaveccia et al., 1988; Gardiner, 
1992; Rouse and Pleijel, 2001). Although in most polychaete species circular fibres are usually less developed, total absence of these fibres is regarded as an exceptional case (Lanzaveccia et al., 1988; Gardiner, 1992). However, in contrast to this opinion previous histological and TEM studies (e.g. Mettam, 1967, 1971; Storch, 1968; Hermans, 1969; Tzetlin, 1987; Ivanov and Tzetlin, 1997; Tzetlin et al., 2002a) as well as recent cLSM investigations (Tzetlin et al., 2002b; Filippova et al., 2004; Müller and Worsaae, 2004) demonstrated that circular fibres are missing in an increasing number of polychaete species. Furthermore, Mettam (1976, 1971) pointed out that transverse muscle elements actually belonging to the parapodial muscle complex might have erroneously been interpreted as circular fibres. This contradictory information necessitates reinvestigation and complementation of present data as well as the examination of more samples in order to answer more general questions, e.g. how the muscles of the annelidan stem species were organized. Such broad-scale studies can be carried out by phalloidin-labelling and confocal laser scanning microscopic analysis, a combination that has already proved valuable in other invertebrate taxa with small specimens (e.g. Müller, 1999; Möllers and Müller, 2001; Tzetlin et al., 2002b; Müller and SchmidtRhaesa, 2002; Müller et al., 2004; Müller and Sterrer, 2004).

In the present paper this method was applied to the dorvilleid polychaete Dorvillea kastjani Tzetlin,1980 (Fig. 1) and the muscular architecture of the prostomium (pr), palps (p), body wall (bw), intestine (i) and parapodia (pp) of the species are described. In order to prevent confusion we intro-

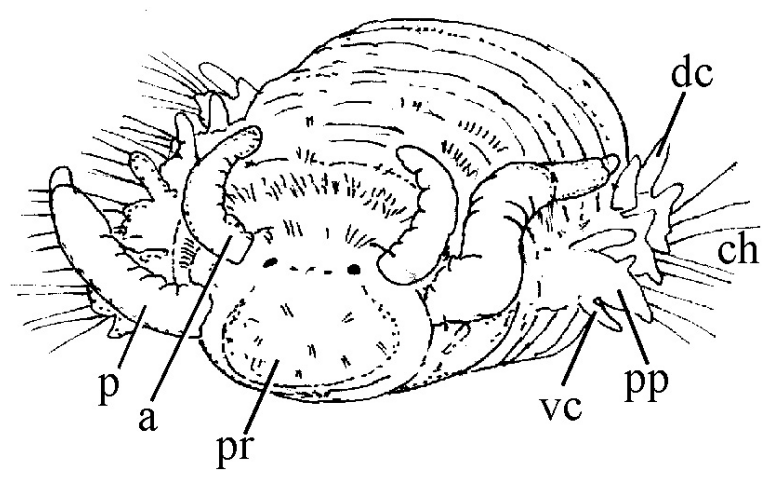

FIG. 1. - Dorvillea kastjani, schematic drawing of the anterior end (after SEM image), frontal view; a, antenna; ch, chaetae; dc, dorsal (notopodial) cirrus; vc, ventral (neuropodial) cirrus; p, palp; pp, parapodium; pr, prostomium. duce a new nomenclature in which the above abbreviations for the body sections are complemented by orientation as well as location of the muscles, e.g., "pr/t1" indicates "prostomial transverse muscle 1 ". To keep the abbreviations short, a character for "muscle" is generally omitted. Furthermore, all muscles oriented perpendicular to the anterior-posterior body axis are termed "transverse muscles". Only transverse fibres encircling the entire body as a complete ring in a supralongitudinal position will be called "circular muscles".

\section{MATERIALS AND METHODS}

The investigated specimens of Dorvillea kastjani were collected at the biological station Kartesch in the White Sea. Three complete specimens and two dissected single segments were analyzed; the latter were prepared in order to get z-stacks of cross sections and the parapodia.

The organisms were anesthetized for $10 \mathrm{~min}$ in $8 \% \mathrm{MgCl}_{2}$ solution and subsequently fixed on ice overnight in $4 \%$ paraformaldehyde in $0.15 \mathrm{M}$ phosphate-buffered-saline (PBS; pH 7.4) containing 12 $\%$ sucrose. After rinsing, specimens were preincubated in PBT (PBS with $0.1 \%$ Triton X-100) for $1 \mathrm{~h}$ and then incubated in FITC- (fluorescein isothiocyanate) labelled phalloidin-solution (5 $\mu 13.3 \mu \mathrm{M}$ solution in $100 \mu 1 \mathrm{PBS})$. Specimens were embedded in Citiflour (Plano) between two cover slips and investigated with a Zeiss LSM 410 confocal laser scanning microscope. Z-stacks were projected into maximum-intensity pixel images (MIP). The 3-D arrangement of stained structures can be deduced from the colours, which follow the spectral light from red peripherally to dark blue centrally. Image adjustment was carried out with Adobe Photoshop 7.0 and arrangement of plates with Adobe Illustrator 7.0 and 10.0 .

\section{RESULTS}

\section{Musculature of the anterior end}

The prostomium of Dorvillea kastjani is penetrated by three pairs of more or less longitudinally oriented muscles that attach at five sites. The architecture is complemented by two transverse and numerous radially oriented fibres. 

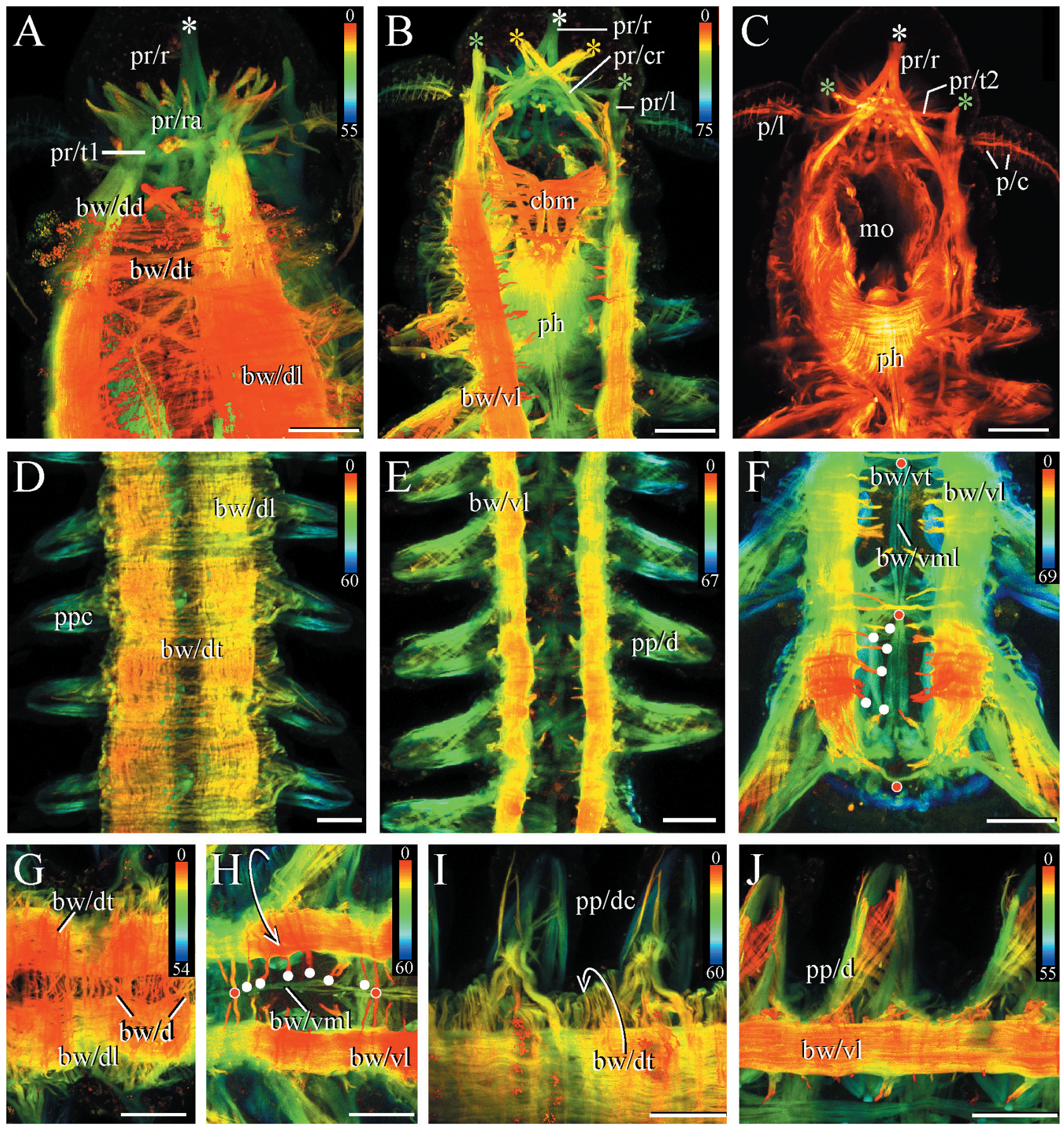

FIG. 2. - Dorvillea kastjani, F-actin muscular subset of adult specimens, depth coded images (apart from C). Anterior end to the top (A-F) or to the left (G-J). A-C, anterior end. A, dorsal view, antennae broken off; the prostomial rostral muscles (pr/r) attach medially (white asterisk); bw/dd, bw/dl, bw/dt, bracing, longitudinal and transversal muscles of the body wall; $\mathrm{pr} / \mathrm{t} 1, \mathrm{pr} / \mathrm{ra}$, first transverse and radial muscles of the prostomium. B, ventral view; the prostomial cross muscles ( $\mathrm{pr} / \mathrm{cr}$ ) attach at two paramedial (yellow asterisks) and the prostomial longitudinal muscles (pr/l) at two peripheral (green asterisks) sites; cbm, circumbuccal complex, ph, pharynx, bw/vl, ventral longitudinal muscles. $\mathrm{C}$, ventral view, most ventral sections omitted; a second transverse muscle (pr/t2) stretches between the peripheral attachment sites; $\mathrm{p} / \mathrm{c}, \mathrm{p} / \mathrm{l}$, circular and longitudinal palp muscles; mo, mouth opening. D, dorsal view of trunk segments; ppc, parapodial complex. E, ventral view of trunk segments; pp/d, diagonal muscles of parapodia. F, ventral view of posterior two segments; ventral transverse muscles (bw/vt) are connected within the intersegmental furrow (red spots) and terminate before the midline (white spots); bw/vml, ventromedian longitudinal muscle. G, close-up of dorsal side. H, close-up of ventral side. I, dorsal view of parapodia with muscles running into the dorsal cirri (pp/dc). J, ventral view of parapodia. Scale bars: $\mathrm{E}, \mathrm{H}=50 \mu \mathrm{m}$, all others $25 \mu \mathrm{m}$.

At the transition between peristomium and prostomium the dorsolateral longitudinal strands become thin bundles running anteriorly and medially. Near the anterior prostomial margin these rostral muscles unite and form the anteriormost medial attachment site (Figs. 2A-C, 3A). They are basally interconnected by 


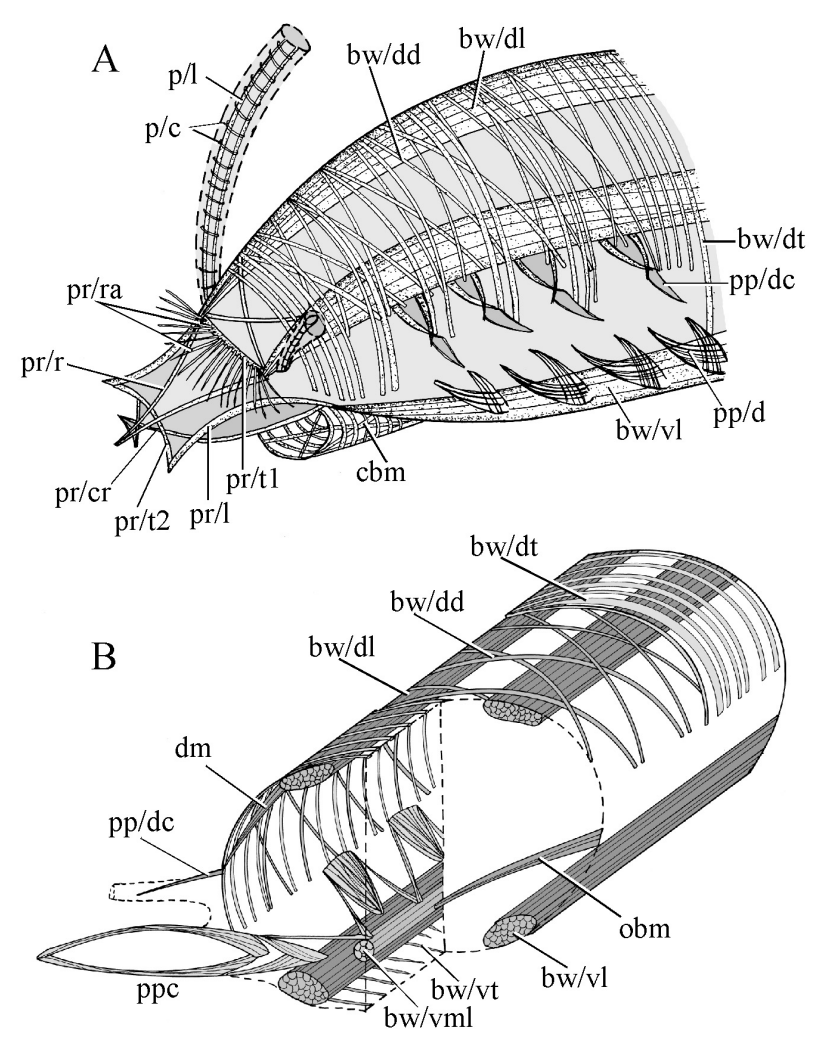

FIG. 3. - Dorvillea kastjani, schematic drawings of the muscular architecture of adult specimens. A, dorsolateral view of the anterior end. B, frontal view of trunk section; $\mathrm{pr} / \mathrm{cr}, \mathrm{pr} / \mathrm{l}, \mathrm{pr} / \mathrm{r}$, prostomial cross, longitudinal and rostral muscles; $\mathrm{pr} / \mathrm{ra}, \mathrm{pr} / \mathrm{t} 1, \mathrm{pr} / \mathrm{t} 2$, radial, first and second transverse prostomial muscles; $\mathrm{p} / \mathrm{c}, \mathrm{p} / \mathrm{l}$, circular and longitudinal palp muscles; cbm, circumbuccal muscles; bw/dd, bw/dl, bw/dt, bracing, longitudinal and transverse muscles of the dorsal body wall; pp/dc, muscles of the dorsal cirrus; $\mathrm{pp} / \mathrm{d}$, diagonal parapodial muscles; bw/vl, bw/vml, bw/vt, ventral and ventromedian longitudinal and transverse muscles of the ventral body wall; obm, oblique muscles; dm, diagonal muscles, ppc, parapodial complex.

a transverse muscle (pr/t1), giving the whole arrangement a triangular shape. A distinct structure is formed by muscles that extend radially from the transverse muscle in a semicircular pattern (Figs. 2A, 3A). The prostomial longitudinal $(\mathrm{pr} / \mathrm{l})$ and the more ventrally located cross muscles $(\mathrm{pr} / \mathrm{cr})$ are elongations of the ventral longitudinal strands. The longitudinal muscles extend anteriorly either straight or in an inwardlydirected arc. Their terminations form the two most posterior and peripheral attachment sites (Figs. 2B, C, $3 \mathrm{~A})$, which are linked to each other by the inward curving second transverse muscle (pr/t2). The prostomial cross muscles encircle the mouth and extend in a sweep anteriorly and medially. By crossing each other they form a distinct medioventral chiasma (Fig. 2B) but terminate a few micrometres further anterior at the contralateral side. Together with fibres from the same body side, the cross muscles form a pair of paramedial attachment sites (Figs. 2B, 3A).
Whereas no F-actin fibres could be recognized within the antennae, two muscular layers are present in the palps. In each palp two longitudinal strands run centrally towards the tip. They are surrounded by circular fibres which are widely separated from each other, so that both layers form a loose arrangement (Figs. 2C, 3A).

Within the peristomium a circumbuccal complex demarcates the posterior margin of the mouth opening (Fig. 2B). It consists of an outer layer of transverse and an inner layer of diagonal muscles. The latter are in contact with the massive muscular jaw apparatus. The pharynx, located in the anterior two parapodial segments, is made up of several dense layers of longitudinal and transverse fibres (Fig. 2C).

\section{Musculature of the body wall}

Dorsally in the body wall three muscular layers can be identified, which, from the outside to the centre, contain: transverse, bracing and longitudinal fibres. The transverse fibres run laterally and diverge to surround the parapodia anteriorly and posteriorly. They are absent in the anterior region of the peristomium (Figs. 2A, 3A). The bracing muscles cover the area between the dorsal bases of the parapodia. By extending from one segment to the contralateral side of an adjoining segment they form distinct chiasmata in the dorsal midline (Figs. 2A, $3 \mathrm{~A}$ ). While they are irregularly separated within the anterior two-thirds of the trunk, their arrangement is more regular in the posterior end. Due to lack of dorsal transverse fibres in the peristomium, the anteriormost chiasma is very conspicuous (Figs. 2A, 3A). The longitudinal fibres are concentrated in two massive dorsolaterally located strands with diminishing diameter anteriorly and posteriorly. Within the trunk they run in parallel within a distance of about 10 micrometres, indicated by a fibre-free area between them (Figs. 2D,G, 3A).

On the ventral side only two layers are present and bracing muscles are absent. The dorsal transverse muscles elongate and run ventrally and medially from the anterior regions of the parapodia along the lateral walls between them. Only those within the intersegmental furrows reach the midline and interconnect with those on the other side (Fig. 2F, H, red spots). The others are concentrated into six or seven symmetrically arranged pairs (Fig. 2F, H, white dots) that terminate paramedially, approxi- 


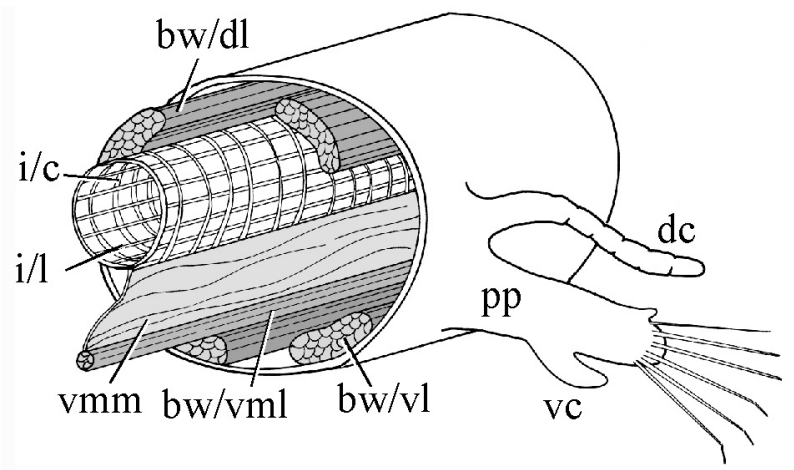

FIG. 4. - Dorvillea kastjani, schematic drawing of the intestinal musculature; bw/dl, bw/vml, bw/vl, dorsal, ventromedial and ventral longitudinal muscles of the body wall; $\mathrm{i} / \mathrm{c}, \mathrm{i} / \mathrm{l}$, circular and longitudinal muscles surrounding the intestine; vmm, ventral mesentery muscle.

The parapodia (pp) possess dorsal (dc) and ventral (vc) cirri.

mately 10 micrometres apart (Fig. 2E, F, H). The longitudinal fibres are clustered in three distinct bundles, of which the two ventral ones lie approximately 25 micrometres apart. The single medioventral strand is smaller in diameter and lies more dorsally, above the ventral nerve cord (Fig. 3B).

Because of its myoepithelial constitution the ventral mesentery, spreading between the ventromedian longitudinal muscle strand and the gut, is labelled with F-actin as well (Fig. 4). Beneath the body wall musculature diagonalmuscles extend from the dorsal longitudinal strands ventrally. Oblique muscles run from the ventromedian longitudinal strand towards the neuropodia.

\section{Intestinal musculature}

The entire intestine is encircled by a regular grid of evenly spaced longitudinal and perpendicular circular fibres. The latter, located more peripherally, face the body cavity and the inner longitudinal fibres face the lumen of the gut (Fig. 4).

\section{Parapodial musculature}

While Dorvillea kastjani possesses only dorsal cirri as remnants of the notopodia, its neuropodia are well developed (Fig. 4). At the dorsal base of the dorsal cirrus the diagonalfibres bend outward and penetrate the cirrus, within which they terminate after a short distance (Figs. 2I, 3B). Within the neuropodia six different types of muscles can be differentiated (Fig. 5). The parapodial body wall contains longitudinal and diagonal fibres, the former of which lying more centrally and running straight from the parapodial base to the tip. Muscles inserting anteriorly and posteriorly of the neuropodia fan out radially and, by crossing over the diagonal fibres, form a regular lattice (Figs. 2J, 5A). Muscles from which the chaetae protrude insert at
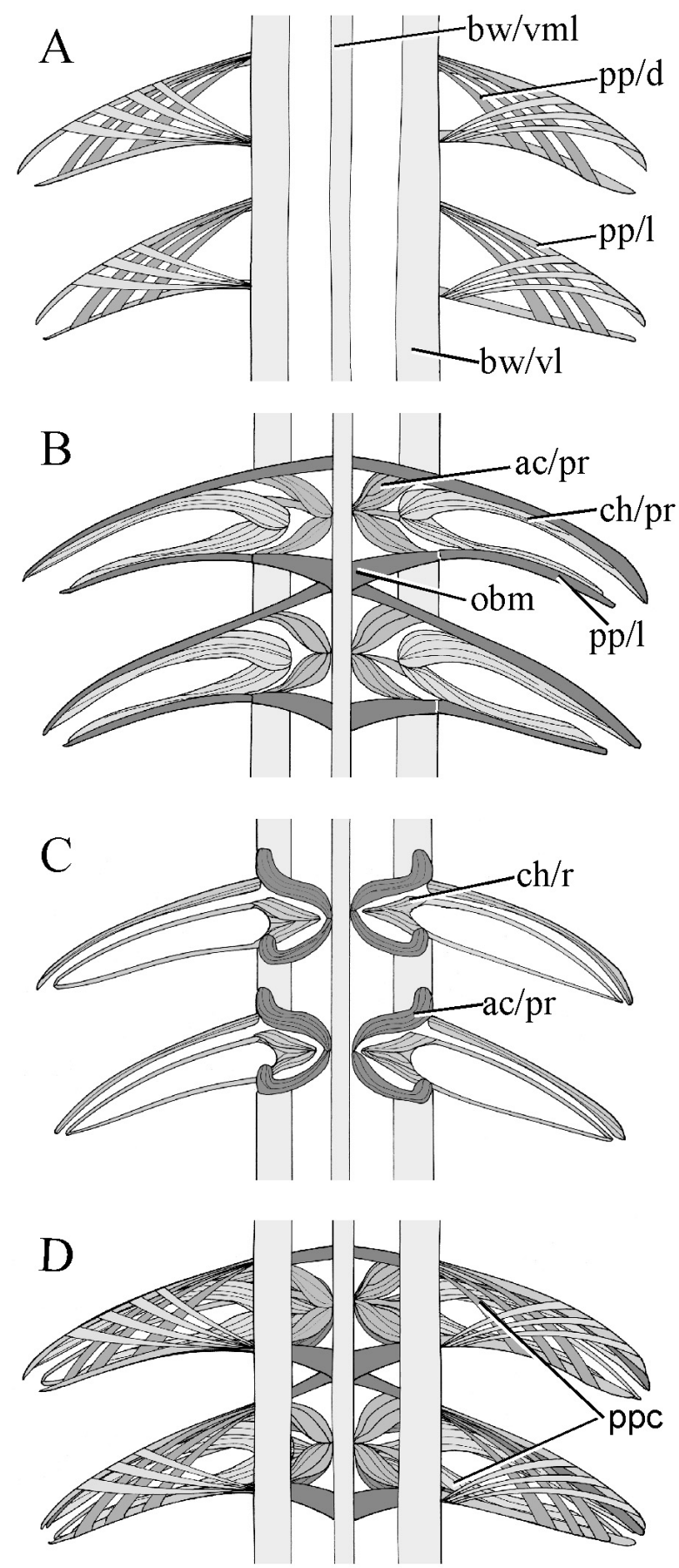

FIG. 5. - Dorvillea kastjani, schematic drawings of the parapodial musculature. A, ventral view, only longitudinal ( $\mathrm{pp} / \mathrm{l})$ and diagonal (pp/d) parapodial musculature shown; vml, vl, ventomedian and ventral longitudinal muscles. B, dorsal view; acicular $(\mathrm{ac} / \mathrm{pr})$ and chaetal (ch/pr) protractor muscles. Oblique muscles (obm) attach to the parapodia. C, dorsal view; chaetal protactor $(\mathrm{ch} / \mathrm{pr})$ and acicular protractors $(\mathrm{ac} / \mathrm{pr})$ lie fairly central. D, ventral view of entire arrangement; ppc, parapodial complex. 
their bases (Fig. 5B) and in surrounding them these chaetae-protruding muscles form the so-called chaetal sacs. More centrally, muscles insert in the same manner at the aciculae. The chaetal retractor muscles extend to the midventral line (Fig. 5C), as do the acicular muscles.

\section{DISCUSSION}

As early as 1962 Clark pointed out that in members of the Dorvillidae the longitudinal muscles are concentrated in bundles. In fact, the resemblance of the fundamental muscular organization of Dorvillea kastjani to that of other polychaetes (Gardiner, 1992; Rouse and Pleijel, 2001; Purschke, 2002) is ascribable to the dominating dorsolateral and ventral longitudinal strands. This feature has been used as a key character in phylogenetic analyses of annelids (Rouse and Fauchald, 1997). Presence of an additional ventromedian strand, which in most cases is located dorsal to the two ventral ones and above the ventral cord, turns out to be a common feature within polychaetes (Filippova et al., 2004; Müller and Worsaae, 2004). The median longitudinal muscle might function as an attachment site for the medially extending muscles of the parapodial complex. The following discussion will focus on more unique structures of $D$. kastjani, namely the prostomial and parapodial muscles as well as the transverse and the circular muscles of the body wall.

\section{Muscles of the anterior end}

At least the longitudinal muscles within the prostomium are nothing else but elongations of the longitudinal trunk muscles. Importance of the ventral strands is emphasized by the fact that they are the only fibres to penetrate the prostomium in Magelona cf. mirabilis and Prionospio cirrifera (Filippova et al., 2004) and are the dominant fibres in Nerillidae (Müller and Worsaae, 2004). They might be more important and prominent than the dorsal fibres because they follow the course of the nervous system and encircle the mouth opening, and thus ensure flexibility of that region. The medial elongations and crossing over of the fibres observed in D. kastjani are already known from other polychaetes (Müller, 1999) as well as from other invertebrates (e.g. Platyhelminthes: Rieger et al., 1994; Gnathostomulida: Müller and Sterrer, 2004). This arrangement enables not only contraction but also rotational movements of the prostomium. On top of this the two transverse fibres in D. kastjani allow bilateral compression. The course of muscles within the prostomium is highly variable within polychaetes: whereas they terminate at five attachment sites in D. kastjani, they form scaffoldings of muscle fibres in a lattice-like arrangement, shaping the prostomium in, e.g. Nerillidae (Müller and Worsaae, 2004), Ctenodrilidae and Dinophilidae (M.C.M Müller, unpublished data). Elongations of the dorsal longitudinal muscles contribute greatly to these trestles. Our current knowledge is insufficient to attribute the different constructions to a specific life style (food uptake, habitat, digging) or to account for them using morphological characters, e.g. absence or presence and insertion of prostomial appendages. Thus, the importance of the specific structure of this musculature for phylogenetic considerations within polychaetes still has to be evaluated.

The loose arrangement of circular and central longitudinal fibres in the palps indicates limited flexibility of these prostomial appendages in $D$. kastjani compared with appendages in Spionida (Filippova et al., 2004). In fact, they function as carriers of sensory organs and are not involved in food capture and uptake. Lack of muscles within the antennae is astonishing, because even in the small interstitital species of Nerillidae the antennae contain well developed muscles (Müller and Worsaae, 2004). They can be moved as a whole by muscles inserting at their bases; such muscles, however, have not been documented herein.

The circumbuccal complex of D. kastjani resembles that of Prionospio cirrifera (Filippova et al., 2004), apart from containing diagonal instead of longitudinal fibres. In containing only transverse fibres the more simple circumbuccal complex of Magelona cf. mirabilis (Filippova et al., 2004) looks like the postoral ventral region with transverse fibres in the second segment of Nerilla antennata and Nerillidium sp. (Müller and Worsaae, 2004). Because in the latter the transverse fibres are located beneath the oesophagus, the authors concluded that the transverse fibres create a peristaltic wave, supporting transportation of food particles from the oesophagus to the stomach. It can also be surmised that the circumbuccal complexes support extrusion of the tongue or pharyngeal bulb. 


\section{Transverse and circular fibres of the body wall}

Dorvillea kastjani does possess true circular fibres in a supralongitudinal position, i.e. between epidermis and longitudinal muscles. They are easily overlooked because of the small diameter, the location within the intersegmental furrow and the difficulty of tracing them around the entire body. Dorsally they cannot be distinguished from the other numerous transverse fibres. These, however, also encircle the body but do not interconnect ventrally, and thus produce incomplete rings. The circular fibres might act as sphincters, separating one segment from the other, but no functional explanation can be given as to why the other fibres become concentrated into a few strands and terminate paramedially. However, this gap on the ventral side corresponds to the position of the ventral nerve cord, which probably has a basiepithelial position in $D$. kastjani. Such a basal-epithelial position seems to be a common feature in polychaetes, not restricted to small and progenetic species only (see Purschke, 2002; Tzetlin et al., 2002a). As has been observed in other polychaetes, the region of the ventral nerve cord that bulges into the body cavity is devoid of transverse muscle fibres. Further TEM studies would be required to verify these data and reveal how the true circular fibres located within the intersegmental furrows surround the nerve cord. The position of the ventral nerve cord might also be correlated with the inward position of the unpaired ventromedial longitudinal muscle strand. The transverse fibres seem to be pushed aside anteriorly and posteriorly by the outgrowing parapodia instead of following the extension of the body wall. Therefore, the transverse fibres do not contribute to the parapodial musculature. Studies on myogenesis are needed to clarify whether the transverse fibres are reduced circular muscles and whether a supposed lattice-like arrangement of longitudinal and regularly arranged circular fibres is superimposed by parapodia formation.

\section{Muscles of the parapodial complex}

Comparison between polychaete species reveals many common traits of parapodial muscles (Mettam, 1971). Because of similarity of function, e.g., protrusion and retraction of chaetae and aciculae, this is not unexpected. Detailed investigations, however, show enormous interspecies differentia- tions: Mettam (1971) described 39 muscle types for Aphrodita sp. while Tzetlin and Fillipova (2004) documented 20 for Nereis sp. and in the present paper eight are reported for Dorvillea kastjani. While the muscular equipment of the body wall and chaetal apparatus is identical, the differences between the species can be attributed to the lack of so-called inner muscles of the parapodium. In species possessing numerous parapodial muscles, e.g., members of Chrysopetalidae and Aphroditidae (Mettam, 1971; Tzetlin et al., 2002a), the appendages are located dorsally and the chaetae point upward, most likely to ward off potential predators. The organisms are more or less passive and do not use their parapodia for active locomotion. Based on morphological and behavioural data, and regarding the chrysopetalid condition as basal, Westheide and Russel (1997) concluded that polychaete parapodia primarily had a defensive rather than a locomotory function. In polychaetes using their parapodia for locomotion the appendages insert laterally and are actively moved backwards and forwards; some species use them even for swimming during certain life stages (e.g. Nereis). Massive muscles, needed for stiffening the defensive parapodia, would be disadvantageous and in fact few bundles with particular functions are present in mobile species. Müller and Worsaae (2004) recently pointed out that massive parapodial muscles are also present in taxa that use their parapodia as anchor devices within the interstitial tissue, e.g., Nerillidae. A striking difference between Nerillidae and Dorvilleidae is the architecture of the chaetal sacs: whereas they are formed by dorsal and ventral oblique muscles in Nerillidae, only chaetae- and aciculae-protractors form them in Dorvilleidae. The unique nerillid parapodia and their muscular arrangement probably represent an aberrant condition.

\section{REFERENCES}

Clark, R.B. - 1962. On the structure and functions of polychaete septa. Proc. Zool. Soc. Lond., 138: 543-578.

Filippova, A., G. Purschke, A.B. Tzetlin and M.C.M. Müller. 2004. Musculature of Magelona cf. mirabilis (Magelonidae) and Prionospio cirrifera (Spionidae) shown by phalloidin labelling and cLSM. Zoomorphology, 124: 1-8.

Gardiner, S. - 1992. General organization, integument, musclulature, coelom and vascular system. In: F.W. Harrison (ed.), Microscopic Anatomy of Invertebrates Vol. 7, pp. 19-52, Wiley-Liss, New York.

Hermans, C.O. - 1969. The systematic position of the Archiannelida. Syst. Zool., 18: 85-102.

Ivanov, I.E. and A.B. Tzetlin. - 1997. Fine structure of the trunk in the polychaete family Phyllodocidae (Annelida, Polychaeta): a 
functional morphological analysis. Doklady Akademii NAUK, 354: 272-277b (in Russian).

Lanzavecchia, G., M. de Eguileor and R. Valvassori. - 1988. Muscles. In: W. Westheide and C.O. Hermans, (eds.), The Ultrastructure of Polychaeta. Microfauna Marina, 4: 71-88, Gustav Fischer, Stuttgart.

Mettam, C. - 1967. Segmental musculature and parapodial movement of Nereis diversicolor and Nephthys hombergi (Annelida: Polychaeta) J. Zool., 153: 245-275.

Mettam, C. - 1971. Functional design and evolution of the polychete Aphrodite aculeata. J. Zool., 163: 489-519.

Möllers, S. and M.C.M. Müller. - 2001. Development of the muscle system in Myzostoma cirriferum (Annelida, Myzostomida). Zoology, 94(1): 41 .

Müller, M.C. - 1999. Das Nervensystem der Polychaeten: Immunhistochemische Untersuchungen an ausgewählten Taxa. PhD Thesis, Universität Osnabrück.

Müller, M.C.M., R. Jochmann and A. Schmidt-Rhaesa. - 2004. The musculature of horsehair worms (Gordius aquaticus, Paragordius varius, Nematomorpha): F-actin staining and reconstruction by cLSM and TEM. Zoomorphology, 123: 45-54.

Müller, M.C.M. and A. Schmidt-Rhaesa. - 2002. Reconstruction of the muscle system in Antygomonas sp. (Kinorhyncha, Cyclorhagida) by phalloidin labelling and cLSM. J. Morphol., 256: $103-110$.

Müller, M.C.M. and W. Sterrer. - 2004. Musculature and nervous system of Gnathostomula peregrina (Gnathostomulida) shown by phalloidin labelling, immunohistochemistry, and CLSM, and their phylogenetic significance. Zoomorphology, 123: 169-177.

Müller, M.C.M. and K. Worsaae. - 2004. CLSM analysis of the phalloidin stained muscle system in Nerilla antennata, Nerillidum sp. and Trochonerilla mobilis (Polychaeta, Nerillidae). J. Morphol., DOI 10.1002/jmor.10285.
Purschke, G. - 2002. On the ground pattern of Annelida. Org. Div. Evol., 2: 181-196.

Rieger, R.M., W. Salvenmoser, A. Legniti and S. Tyler. - 1994. Phalloidin-rhodamine preparations of Macrostomum (Plathelminthes): morphology and postembryonic development of the musculature. Zoomorphology, 114: 133-147.

Rouse, G. W. and K. Fauchald. - 1997. Cladistics and Polychaetes. Zool. Scr., 26: 139-204.

Rouse, G.W. and F. Pleijel.- 2001. Polychaetes. Oxford University Press, New York.

Storch, V. - 1968. Zur vergleichenden Anatomie der segmentalen Muskelsysteme und zur Verwandtschaft der PolychaetenFamilien. Z. Morph. Tiere., 63: 251-342.

Tzetlin, A. - 1987. Structural peculiarities of Pisionidens tchesunovi (Polychaeta) and their possible significance. Zool. Zh. 66: 1454-1462 (in Russian).

Tzetlin, A.B. and A. Filippova. - 2004. Muscular System. In: G. Purschke and T. Bartolomaeus (eds.), Morphology, Molecules, Evolution and Phylogeny in the Polychaeta and related Taxa. Hydrobiologia/Dev. Hydrobiol. 535/536: 113-126.

Tzetlin, A.B., T. Dahlgren and G. Purschke. - 2002a. Ultrastructure of the body wall, body cavity, nephridia and spermatozoa in four species of the Chrysopetalidae (Annelida) Zool. Anz., 241: $37-55$.

Tzetlin, A.B., A. Zhadan, I. Ivanov, M.C.M. Müller and G. Purschke. $-2002 b$. On the absence of circular muscle elements in the body wall of Dysponetus pygmaeus (Chrysopetalidae, Polychaeta, Annelida) Acta Zool., 83: 81-85.

Westheide, W. and C.W. Russell. - 1997. Ultrastructure of chrysopetalid-paleal chaetae (Annelida, Polychaeta). Acta Zool., 73: 197-202.

Received September 20, 2004. Accepted May 11, 2005. 